\title{
POINT/COUNTERPOINT
}

Suggestions for topics suitable for these Point/Counterpoint debates should be addressed to Colin G. Orton, Professor

Emeritus, Wayne State University, Detroit: ortonc@wayne.edu. Persons participating in Point/Counterpoint discussions are

selected for their knowledge and communicative skill. Their positions for or against a proposition may or may not reflect their

personal opinions or the positions of their employers.

\section{Changes and demands in the higher education sector are increasingly making advanced degree medical physics programs nonviable and the profession will have to develop a new model for delivering such education}

\author{
Andrew Fielding, Ph.D. \\ Science and Engineering Faculty, Queensland University of Technology, Brisbane, Qld 4001, Australia \\ (Tel: 61 (0) 423 119471; E-mail: a.fielding@qut.edu.au) \\ Joann I. Prisciandaro, Ph.D. \\ Radiation Oncology, University of Michigan, Ann Arbor, MI 48109, USA \\ (Tel: 734-936-4309; E-mail: joannp@med.umich.edu)
}

Colin G. Orton, Ph.D., Moderator

(Received 24 October 2017; accepted for publication 25 October 2017; published 20 November 2017)

[https://doi.org/10.1002/mp.12645]

\section{OVERVIEW}

At universities, advanced degree programs in Medical Physics tend to have relatively few students compared to, for example, programs in other Physics subspecialties. This tends to make them relatively more expensive to operate, and since universities are always looking for ways to reduce costs, there is some concern that such programs will cease to be affordable and other ways to educate medical physicists should be developed. This is the premise debated in this month's Point/Counterpoint.

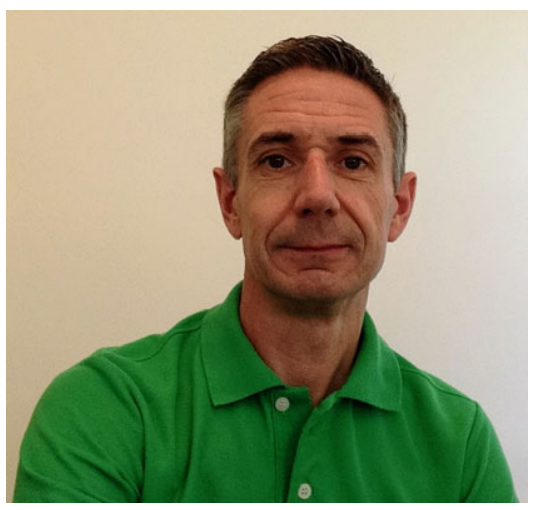

Arguing for the Proposition is Andrew Fielding, Ph.D. Dr. Fielding earned a B.Sc. (Hons.) in Physics with Medical Physics from the University of Surrey, UK and a Ph.D. (thesis title: Final State Effects in Neutron Compton Scattering) from the University of Portsmouth, UK. He then spent 4 years at the Institute of Cancer Research/Royal Marsden Hospital, UK, carrying out postdoctoral research in the radiotherapy research group. He currently holds the position of Senior Lecturer in the Science \& Engineering Faculty at Queensland University of Technology (QUT) in Brisbane, Australia. He is also the course coordinator of the Graduate Diploma and Master of Applied Science programs in Medical Physics at QUT. Dr. Fielding is a member of the Institute of Physics, obtained Chartered Physicist status in 2001, and is a full member of the Australasian College of Physical Scientists and Engineers in Medicine (ACPSEM). He is the university representative on the ACPSEM Professional Standards Board. Dr Fielding's research interests are focused on medical imaging and radiation therapy.

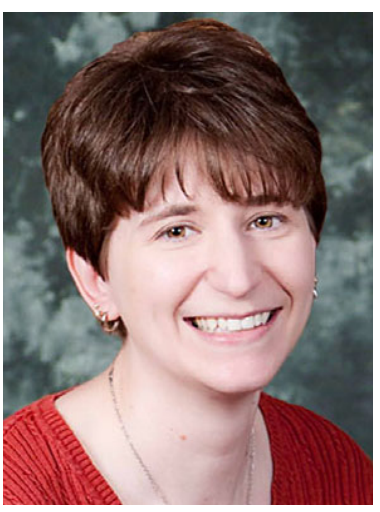

Arguing against the proposition is Joann I. Prisciandaro, Ph.D. Dr. Prisciandaro received her Ph.D. in chemical physics from Michigan State University in 2001. Following graduation, she worked as a research fellow in the Department of Radiation Oncology at the Mayo Clinic in Rochester, Minnesota. In 2004, she joined the clinical faculty at the University of Michigan. Her main areas of focus have been brachytherapy, radiation safety, and education. She was the director of the department's medical physics residency program for 8 years and has just recently transitioned to be the associate director of the residency program. Dr. Prisciandaro is an active member of a number of AAPM educational, scientific, and professional committees, subcommittees, working groups, and task groups, and currently chairs the Education and Training of Medical Physicists Committee. She is a member of the Commission on Accreditation of Medical Physics Education Programs (CAMPEP) Board of Directors and chaired the AAPM Work Group on Periodic Review of Medical Physics Residency Training. She has also served as a member of the ASTRO Subcommittee on Physics Curriculum for Residents and is a member of the IOMP Education and Training Committee. 
FOR THE PROPOSITION: Andrew Fielding, Ph.D.

\section{Opening Statement}

There has, for some years, been a drive in most countries to increase participation in higher education while simultaneously trying to cut the cost of delivering it. This has put increasing financial pressure on universities, challenging their business models, and forcing them to closely scrutinize the programs that they offer. ${ }^{1}$ This is particularly the case for advanced degree programs such as Medical Physics that typically are more specialized and attract relatively low numbers of students and therefore less income. At the same time, there has been an increasing corporatization of the university sector with a strong focus on academic performance (at organization and individual levels), international ranking status, and improving financial performance and operating surpluses. If we focus on the enrollments, the CAMPEP (Commission on Accreditation of Medical Physics Education Programs, Inc) graduate program report in 2016 indicated that, in 2015, the number of graduate program entrants matriculating into the 49 accredited programs was 294 students. $^{2}$ This averages less than 6 students per program, which is not going to generate the income required to make a program financially viable. Similar enrolment numbers exist in the six accredited medical physics programs in Australia. Of course, there may be a nonuniform distribution of student enrolments, with some large programs and some smaller programs, but I would argue that even the large programs are going to struggle to demonstrate financial viability if only student-fee-based income is taken into account. I would therefore like to make the point that a large number of small programs being delivered on campus is not sustainable in the long term and traditional medical physics graduate programs are at risk in the near future. This would create a problem for the medical physics profession.

In recent years, a transformation has been going on in higher education with increasing use of digital technology to enhance the learning experience for students. For some years, our organization has been recording all lectures digitally and making them available for students through an online learning system (Blackboard, Inc, Washington D.C., USA). The online system also allows multimedia, online tutorials and quizzes, and discussion groups, to be used to enhance student learning through the use of blended learning techniques. ${ }^{3-5}$ Further research is required on the best way these digital technologies could be used in medical physics graduate programs. ${ }^{6,7}$ The current generation of students expect and are comfortable with this form of blended learning, with many choosing only limited regular direct engagement with the lecturer or tutor. ${ }^{8}$ This online delivery creates an opportunity for increased inter-university collaboration in the delivery of the required knowledge and content for the medical physics graduate student, with the extreme scenario being a single-centralized graduate medical physics program, supported by academic and clinical faculty across a distributed network of universities and hospitals. This would be more cost effective, enable changes and advances relevant to the profession to be implemented in a more agile manner, and be more flexible for students in geographically remote regions.

\section{AGAINST THE PROPOSITION: Joann I. Prisciandaro, Ph.D. \\ Opening Statement}

The training pathway for Medical Physicists in North America has undergone significant changes in the last decade, following the ABR's announcement of the 2012-2014 decision, which restricted entry into medical physics to those candidates who are graduates of an appropriate CAMPEP program. ${ }^{9}$ The 2012-2014 decision brought with it the realization that entry into the field of medical physics would require formal and standardized didactic and clinical training.

Since the announcement of the 2012-2014 mandate, the number of CAMPEP accredited medical physics graduate programs has increased by a factor of 3.5 (from 15 in 2007 to 52 in July 2017) $)^{2, a}$. With this increase, we have also experienced an increase in the number of MS/MSc and $\mathrm{PhD}$ students completing these programs. The total number of graduates in 2016 was reported to be 227 (138 MS/MSc and $89 \mathrm{PhD}$ ) by program directors ${ }^{2, \mathrm{a}}$. With 107 CAMPEP-accredited residency programs (90 therapeutic and 17 imaging) as of July $2017,{ }^{10}$ and 114 residency positions offered through the 2017 MedPhys Match, ${ }^{11}$ few would argue that the number of graduates currently outpace the number of residency positions. However, from 2011 to 2015, the fraction of MS/MSc graduates entering accredited therapeutic residency programs has remained approximately $25 \%$ and increased slightly from $1 \%$ to $5 \%$ for imaging residencies. ${ }^{2}$ For $\mathrm{PhD}$ graduates, those entering an accredited therapeutic program have varied between $25 \%$ and $47 \%$ in this timeframe and have remained at $6.5 \%$ for those entering imaging residencies. ${ }^{2}$ Similar trends have been observed in the reported MedPhys match rates for ranked applicants. For MS/MSc candidates, the match rate has remained constant from 2015 [40 of 69 ranked candidates (58\%)] to 2017 [42 of $70(60 \%)$ ] and has increased for Ph.D. candidates from 60\% in 2015 (37 of 62) to $89 \%$ ( 42 of 47 ) in $2017^{12, b}$. We do not see a $100 \%$ success rate nor should we expect to. Although unfortunate, this is not unique to our field. Additionally, entry into clinical residencies should not be used as the only measure of success for graduates of medical physics programs. Other common areas of interest pursued by graduates include academia, government, and industry, which do not require board certification, and as a result do not require entry into clinical residencies.

Three years after the implementation of the final phase of the 2012-2014 mandate, within the medical physics community, there still remain mixed emotions of the implications this decision will have on our field. Although I do agree that we have, and continue to experience, some pains from this

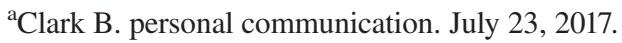

${ }^{\mathrm{b}}$ Antolak JA. personal communication. July 23, 2017. 
transition. As a former medical physics residency program director, I believe that these changes are solidifying our field by ensuring consistency in the fundamental, core, knowledge of junior medical physicists entering residencies, and ultimately the job market. As a result, I believe that our advanced degree medical physics educational programs will continue to be viable.

\section{Rebuttal: Andrew Fielding, Ph.D.}

I agree totally with my opponent that the field of medical physics requires a formal and standardized career pathway that involves didactic and clinical training. In Australia, the pathway requires successful completion of an ACPSEM accredited Medical Physics advanced degree program followed by the completion of the Training, Education, and Accreditation Program (TEAP) in one of the specialty areas of Radiation Oncology, Diagnostic Imaging, or Nuclear Medicine. Australia also has a less than 100\% employment rate for graduates wishing to enter the TEAP program and again, like my opponent, I do not think that this is necessarily a bad situation for the medical physics profession to be in.

The main point that I would like to reiterate is that highly specialized advanced degree programs, with the low enrolments indicated in both the opening statements, are not sustainable or attractive to the modern university. We no longer can assume that universities will continue to be prepared to offer medical physics programs in a way that has remained largely unchanged for 30 years. I think it is crucial and timely that the profession, in partnership with the universities, begins a discussion on how the delivery of advanced degree didactic education in Medical Physics might be reimagined. The Medical Physics 3.0 initiative by the AAPM gives a clear message that, as a profession, we recognize that we cannot stand still in a healthcare world that is rapidly changing. ${ }^{13}$ Many of these changes we probably cannot begin to imagine at this point in time. This is also true for the universities of the future and, as a profession, we need to be aware and ready for any changes that may seriously impact and put at risk the current model of Medical Physics education and training.

\section{Rebuttal: Joann I. Prisciandaro, Ph.D.}

I agree that, in the long term, a large number of small medical physics graduate programs will not be financially viable. At the University of Michigan, classes with low enrollment (e.g., < 7) may be at risk of being canceled or discontinued. One suggestion offered to improve the financial viability of medical physics advanced degree programs is the Doctor of Medical Physics (DMP). ${ }^{14}$ In this model, students are responsible for paying tuition during both their didactic and clinical training. Alternatively, we could allow the free market to correct for the potential surplus in these programs by requiring them to post their residency placement statistics. Loughery et al. ${ }^{15}$ have reported that between 2011 and 2015, placement rates for only ten programs were $>50 \%$; four programs had $0 \%$, and 11 others had $<20 \%$.

I also agree that online educational tools may offer compelling resources to our students, ${ }^{16}$ and that some courses, or a portion of their content, may benefit from online delivery. However, I disagree with Dr. Fielding's idea to transition to a completely online, and in an extreme example, centralized approach. This proposal overlooks the hands-on components of the core graduate curriculum. ${ }^{17,18}$ Additionally, Dr. Fielding has overlooked the importance of research opportunities, which allow our students to gain an appreciation for the scientific method and prepare them to become problem solvers.

The sum total of a medical physics graduate education goes beyond the courses our students complete. It includes the experiences they gain interacting with their fellow students and faculty mentors during the didactic, clinical, and research components of their graduate education. These experiences help our students develop an appreciation, respect, and excitement for our field, and build relationships that result in their personal and academic growth. As in all aspects of our field, change is inevitable. Alternative approaches to medical physics education are worth consideration. However, rather than improving the viability of our postgraduate programs, I believe that Dr. Fielding's approach would result in their demise.

\section{CONFLICTS OF INTEREST}

The authors have no conflicts of interest to disclose.

\section{REFERENCES}

1. Bokor J, Rohan P, Scott M, et al. University of the Future (Ernst and Young, 2012). http://www.ey.com/Publication/vwLUAssets/University_ of_the_future/\%24FILE/University_of_the_future_2012.pdf (Accessed 9 Sept. 2017).

2. Clark B. CAMPEP Graduate Program Report; 2015. http://www.sda mpp.org/resources.php2015.

3. Sharma P. Blended learning. ELT J. 2010;64:456-458. https://academic. oup.com/eltj/article/64/4/456/390082/Blended-learning

4. Petty J. Interactive, technology-enhanced self-regulated learning tools in healthcare education: a literature review. Nurse Educ Today. 2013;33:53-59.

5. López-Pérez MV, Pérez-López MC, Rodríguez-Ariza L. Blended learning in higher education: students' perceptions and their relation to outcomes. Comput Educ. 2011;56:818-826.

6. Kirkwood A. Teaching and learning with technology in higher education: blended and distance education needs 'joined-up thinking' rather than technological determinism. Open Learn. 2014;29:206221.

7. Taylor JA, Newton D. Beyond blended learning: a case study of institutional change at an Australian regional university. Internet Higher Educ. 2013;18:54-60.

8. Owston R, York D, Murtha S. Student perceptions and achievement in a university blended learning strategic initiative. Internet Higher Educ. 2013;18:38-46.

9. Mills MD, Thornewill J, Esterhay RJ. Future trends in the supply and demand of radiation oncology physicists. J Appl Clin Med Phys. 2010;11:209-219.

10. CAMPEP. Accredited graduate programs in medical physics; 2017. http://www.campep.org/campeplstgrad.asp. Accessed July 23, 2017. 
11. National Matching Services Inc. Summary Results of the MedPhys Match for Positions Beginning in 2017; 2017. https://natmatch.com/med phys/stats/2017stats.pdf. Accessed July 23, 2017.

12. Antolak JA, Gibbons JP, Bourland JD. Med-Phys match 2015: a resounding success. AAPM Newslett. 2015;40:20-23.

13. AAPM. MedPhys 3.0; 2016. http://www.aapm.org/MedPhys30/articles/ PhysicsModernMedicine.asp (Accessed 14 September, 2017).

14. Christensen R, Harms T, Hazle L, et al. The Impact of the Professional Doctorate (PD) in Medical Physics (AAPM White Paper); 2008. https:// www.aapm.org/org/committees/WGPDMP/WhitePaperFinalDraftThe ImpactofPDonMedicalPhysicsJuly112008.pdf. (Accessed 14, September 2017).
15. Loughery B, Starkschall G, Hendrickson K, et al. Navigating the medical physics and training landscape. J Appl Clin Med Phys. 2017;18:275287.

16. Prisciandaro JI. Review of online educational resources for medical physicists. J Appl Clin Med Phys. 2013;14:368-387.

17. CAMPEP. Standards for Accrediation of Graduate Educational Programs in Medical Physics. http://www.campep.org/GraduateStandards. pdf. (Accessed September 7, 2017).

18. Paliwal BR, DeLuca PM, Grein EE, et al. Academic Program Recommendations for Graduate Degrees in Medical Physics: Report of the Education and Training of Medical Physicists Committee; 2009. http:// www.aapm.org/pubs/reports/RPT_197.pdf. (Accessed Sept 14, 2017). 